\title{
Complex Hip Spine Syndrome in Young Athlete: A Diagnosis Dilemma
}

\author{
Mohamad Azwan Aziz ${ }^{*}$ and Redzal Abu Hanifah
}

Sports Medicine Unit, Hospital Queen Elizabeth, Malaysia

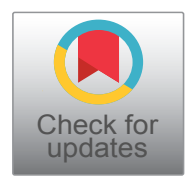

*Corresponding author: Mohamad Azwan Aziz, Sports Medicine Unit, Queen Elizabeth Hospital, Kota Kinabalu, Sabah, Malaysia

\begin{abstract}
Hip spine syndrome is often associated with hip arthrosis and degenerative spine disease affecting the older generation. However, it can also present in young athlete as well. This is a case of 32-years-old male, active body builder with herniated disc L3, L4 and L5 for 5 years presented with acute onset excruciating pain over the anterior portion of his left hip that was affecting his daily living. His clinical examination revealed a classical positive finding of Femoral Acetabular Impingement (FAI) with positive hip provocation tests and MRI confirmed the diagnosis of acute left labral tear of the hip. Patient was offered intra-articular anesthetic hip injection while planning for surgical intervention. The pain did not resolve despite intra-articular injection. This led to the surgeon with the high index of suspicion that the pain was not arising from the left hip but from the spine. Patient was then counselled for laminectomy. Post-operatively, there was a big improvement is seen in pain and disability outcome. A systematic approach is discussed in this report to guide physicians who manage cases of complex Hip Spine Syndrome.
\end{abstract}

\section{Keywords}

Hip, Spine, Hip spine syndrome, Intraarticular hip injection

\section{Introduction}

The term "hip spine syndrome" referring to coexistent of both lumbar and hip pathology. The hip spine syndrome often associated with hip arthrosis with degenerative spine disease, however, it should be considered in young athlete as well. The confusion of where is the primary source of pain often a headache to clinician when hip and spine pathology co-exist together. This account for delay in diagnosing and giving treatment.

The purpose of this case report is to present a young recreational body building athlete with a known case of lumbar pathology complaining of hip pain. Moreover, an algorithm that can be useful in diagnosing the hip spine syndrome is discussed, be useful in correct diagnosis and treatment of complex hip spine syndrome.

\section{Case Report}

This is a case of Mr. D, a 32 Chinese gentleman. He is an active in recreational body building exercise for 10 years with an athletic physique. He was diagnosed with prolapse intervertebral disc in the past 7 years however his condition worsening for the past 3 years with multiple episode of severe back pain requiring admission and he develops reduces sensation over left lower limb at L3 and L4 dermatomes associated with reduced motor power in dorsiflexion of ankle and extension of big toe over left lower limb. His first Magnetic Resonance Imaging (MRI) Spine in 2015 showed left lateral disc prolapse at L2-L3, L3-L4, L4-L5, and L5-S1 with nerve roots compression.

After multiple visit to physiotherapy and clinic review, his condition is improving. His back pain is well controlled with analgesic, his motor power is improving, his sensation is slightly better, and he is able to resume his daily activity and exercise in the gym as usual. However, in June 2018, he develops new symptom of acute excruciating left hip pain disabling him to perform his normal daily living activity. His hip pain is described as anterior hip pain, non-radiating different from sciatica pain that he felt before. His hip pain is aggravated by prolong sitting, after waking up from bed, and prolong standing. His pain score is always 8 to 10 out of 10 with oswetry disability score of 33 . Clinically, he presented

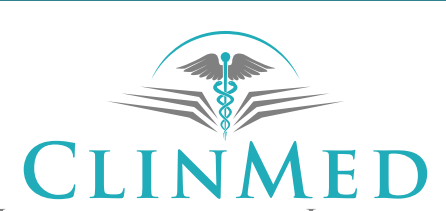

INTERNATIONAL LIBRARY

Citation: Aziz MA, Hanifah RA (2019) Complex Hip Spine Syndrome in Young Athlete: A Diagnosis Dilemma. Int J Sports Exerc Med 5:135. doi.org/10.23937/2469-5718/1510135

Accepted: July 18, 2019; Published: July 20, 2019

Copyright: (c) 2019 Aziz MA, et al. This is an open-access article distributed under the terms of the Creative Commons Attribution License, which permits unrestricted use, distribution, and reproduction in any medium, provided the original author and source are credited. 
with antalgic gait and classical C Sign. His weight is $82 \mathrm{~kg}$ with Body Mass Index of $25.9 \mathrm{~kg} / \mathrm{m}^{2}$. His left hip range of motion is limited especially in internal rotation. His hip provocation test is positive, suggestive of Femoral acetabular Impingement (FAI). His neurological examination is similar from previous clinic review; however, he was unable to perform straight leg test due to excruciating pain of left hip.

History and clinical examination raised high index of suspicion of FAI, thus MRI hip was ordered. His MRI of Left hip confirmed the diagnosis of FAl with labral tear. He was then referred to sports medicine for trial of non-operative management with hip stretching and strengthening exercise. After few sessions, he felt some relief for short while, but the symptom recurred. He was then offered with intra-articular anesthetic injection over left hip, nonetheless, the pain is intractable. This give a surgeon high suspicion that primary source of pain is not from the hip, but from the spine. MRI spine was repeated showing that worsening disc prolapse over the affected side. Thus, he was offered tubular discectomy 2 level (L3 and L4). Post-operatively, he has dramatic improvement in pain with oswetry score of 5 in 1 month.

Table 1: Emergency hip pathology in athlete.

\begin{tabular}{|l|l|}
\hline Emergency hip pain & Non-emergency hip pain \\
\hline $\begin{array}{l}\text { 1. Subluxation with hip } \\
\text { effusion }\end{array}$ & 1. Intraarticular \\
2. Stress fracture & 2. Extra-articular \\
3. Hip dislocation/fracture & \\
4. Septic hip joint & \\
5. Slipped capital femoral \\
Epiphysis
\end{tabular}

\section{Discussion}

The incidence of low back pain in Malaysia is as high as $12 \%$ [1]. One of the worldwide problems of low back pain would be herniated lumbar disc. Jordan J, et al. [2] reported high prevalence of lumbar disc in $3^{\text {rd }}$ until $5^{\text {th }}$ decade age group, males are more susceptible than females by 2:1 ratio [2]. However, herniated lumbar disc can present as an anterior hip pain similar to this case.

For better understanding, hip pain in young athlete can be classified into emergency hip pain and nonemergency hip pain as in Table 1. Non-emergency not arthritic hip pain can be further classified as in Table 2 and Table 3 [3]. Reymond proposed hip spine algorithm for clinician to assess patient in systematic manner to avoid unnecessary surgical intervention as in Figure 1 [4]. The algorithm begins with thorough history and physical examination. A good history taking might help clinician differentiate hip pathology from spine pathology.

If clear diagnosis is made from history and physical examination, the disease should be treated accordingly. However, if the diagnosis is uncertain as in this case, an intra-articular anesthetic hip injection is suggested. Patader and Hungerford conclude that intra-articular hip injection yield $100 \%$ sensitivity, $81 \%$ specificity, $97 \%$ positive predictive value, and $100 \%$ negative predictive value in differentiating hip and spine pathology [5]. Byrd conclude that intra-articular anesthetic injection give accurate results as high as $90 \%$ [6]. However, the gold standard of intra-articular hip injection done under fluoroscopic guidance [7]. Alexander states that Magnetic Resonance Arthrogram can be used concurrent with anesthetic injection and anti-inflammatory drug during the procedure to increase its diagnostic value and temporary pain relief to the in-season athlete [8].

Table 2: Classification of non-arthritic intra-articular hip pathology in athlete.

\section{Intra-articular hip pathology in athlete}

\begin{tabular}{|c|c|c|c|}
\hline Bony & Labral & Capsular & Synovial \\
\hline $\begin{array}{ll}\text { - } & \text { FAI } \\
\text { - } & \text { Hip dysplasia } \\
\text { - } & \text { AVN } \\
\text { - } & \text { Trauma } \\
\text { - } & \text { Infection }\end{array}$ & - Labral & $\begin{array}{l}\text { - Ligamentum Capitis femoris tear } \\
\text { - Capsular laxity }\end{array}$ & $\begin{array}{ll}\text { - } & \text { Tumoral } \\
\text { - } & \text { Enflamatuar }\end{array}$ \\
\hline
\end{tabular}

Table 3: Classification of non-arthritic extra-articular hip pathology in athlete.

\begin{tabular}{|l|l|}
\hline Extra-articular hip pathology in athlete & \multicolumn{2}{l|}{ Hip mimickers } \\
\hline Local & - Sacroiliac Joint Pain \\
\hline - Iliopsoas Tendonitis and Internal Snapping Hip & - Athletic Pubalgia/Sports Hernia/Gilmore's Groin \\
- $\quad$ Gluteus Minimus and Medius Injury & - Osteitis Pubis \\
- Stress Fracture & \\
- Adductor Strain & \\
- Piriformis Syndrome & \\
\hline
\end{tabular}




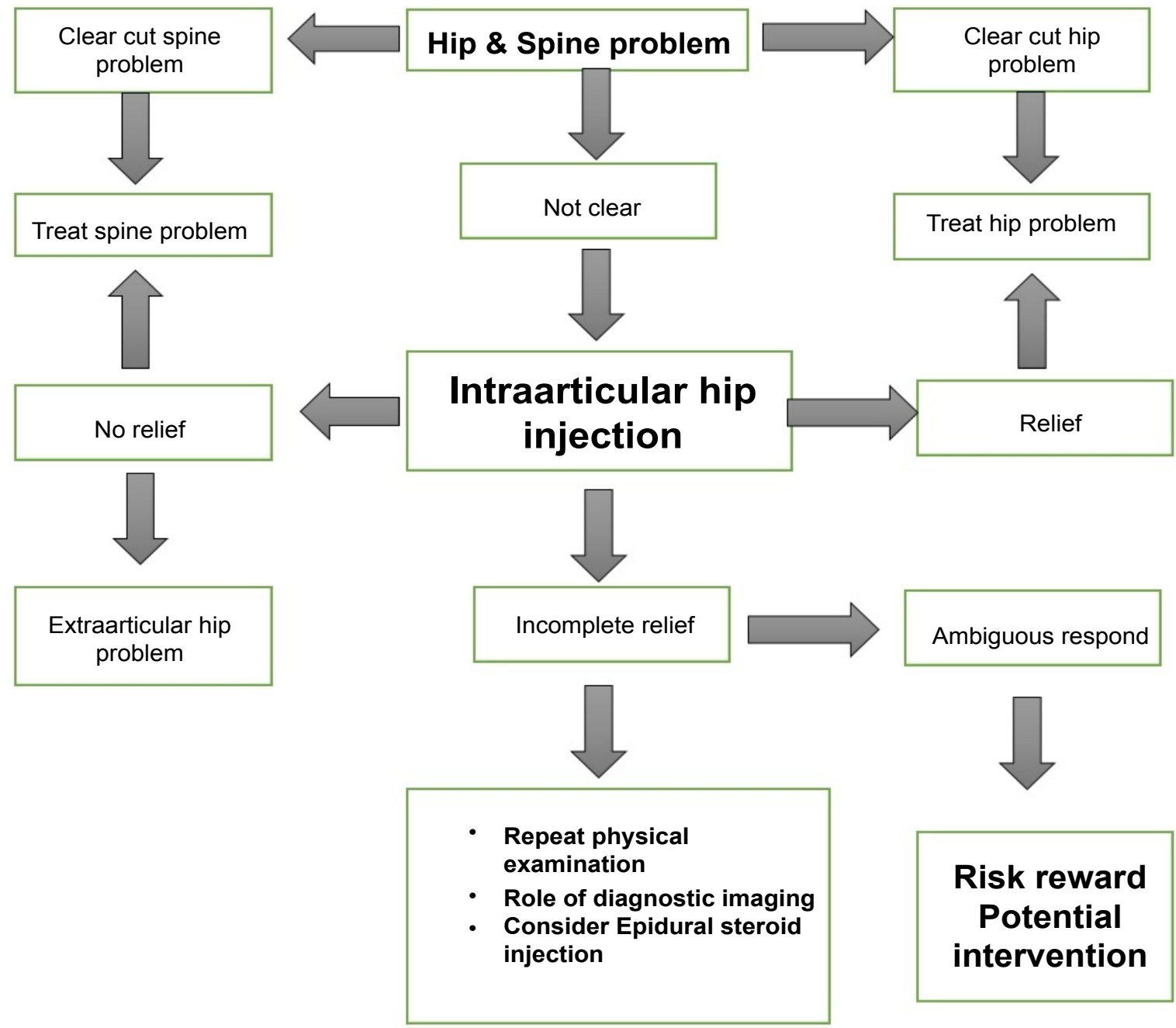

Figure 1: Hip Spine Algorithm.

\section{Risk Reward Potential Intervention}

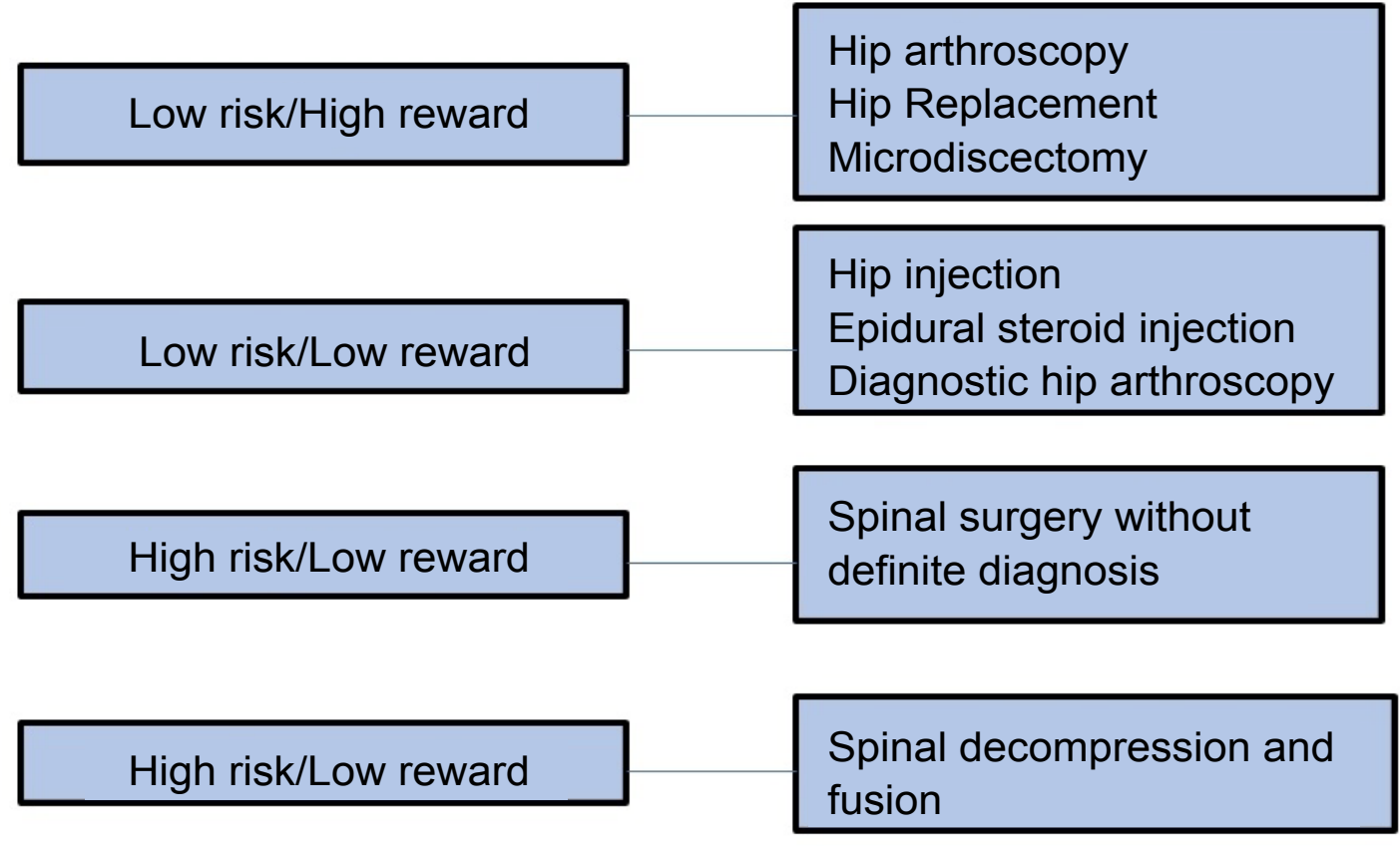

Figure 2: Risk rewards potential intervention. 
If all the above steps fail to determine source of pain, Redmond suggest risk rewards evaluation where benefit and risk of each surgical intervention is taken into consideration. He classifies it into four categories of surgical intervention; low risk/high reward, low risk/low reward, high risk/low reward and high risk/high reward as stated in the Figure 2. In low risk/low rewards intervention such as hip injection, epidural injection and diagnostic arthroscopy, it carries low risk of complication and provides shorts term relieved to patient, thus it is more suitable for diagnostic purposes. In the low risk/high rewards, it is a curative procedure and it has a low risk in young athlete. For this case, the risk reward was stratified into low risk/high rewards where microdiscectomy was performed. Patient had significant improvement after 1 month with no complication of the surgery.

\section{Conclusion}

Hip Spine Syndrome should be address not only in elderly, but in young athlete as well. It should be emphasized that both hip and spine can give rise to source of pain, however, systematic assessment should be performed to determine primary source of pain that cause disability to the patient. Intra-articular hip injection is highly recommended in case where presence of diagnosis dilemma. In an uncertain diagnosis, author recommended risk rewards assessment of intervention after careful consideration and discussion with experience subspecialty.

\section{Acknowledgement}

The authors would like to thank the Director Gen- eral of Health Malaysia for his permission to present this result. A token of appreciation also to Dr. Mariam George Mathew, Head of Sports Medicine Queen Elizabeth Hospital for encouraging us into research field.

\section{Conflict of Interest}

The authors declare that there is no conflict of interest in this study.

\section{References}

1. Mansor, Marzida (2009) The Malaysian LOW BACK PAIN management Guidelines. First Edition. MSA and Spine Society Malaysia, Pfizer.

2. Jordan J, Konstantinou K, O'Dowd J (2009) Herniated lumbar disc. BMJ Clin Evid 2009.

3. Stubbs AJ, Atilla HA (2016) Hip restoration algorithm. Muscles Ligaments Tendons J 6: 300-308.

4. Redmond JM, Gupta A, Nasser R, Domb BG (2015) The hip-spine connection: understanding its importance in the treatment of hip pathology. Orthopedics 38: 49-55.

5. Pateder DB, Hungerford MW (2018) Use of fluoro-scopically guided intra-articular hip injection in differentiating the pain source in concomitant hip and lumbar spine arthritis. Am J Orthop (Belle Mead NJ) 36: 591-593.

6. Byrd JW, Jones KS (2004) Diagnostic Accuracy of Clinical Assessment, Magnetic Resonance Imaging, Magnetic Resonance Arthrography, and Intra-Articular Injection in Hip Arthroscopy Patients. Am J Sports Med 32: 1668-1674.

7. Lesher JM, Dreyfuss $P$, Hager N, Kaplan M, Furman M (2008) Hip joint pain referral patterns: a descriptive study. Pain Med 9: 22-25.

8. Weber AE, Jacobson JA, Bedi A (2013) A review of imaging modalities for the hip. Curr Rev Musculoskelet Med 6: 226234. 